Sharif University of Technology
Scientia Iranica
SCIENTIA $\quad \begin{gathered}\text { Transactions D: Computer Science ES Engineering and Electrical Engineering } \\ \text { http://scientiairanica.sharif.edu }\end{gathered}$

\title{
DTC-SVPWM of an energy storage flywheel associated with a wind turbine based on the DFIM
}

\author{
A. Moualdia ${ }^{a, *}$, A. Medjber ${ }^{a}$, A. Kouzou ${ }^{b}$, and O. Bouchhida ${ }^{a}$ \\ a. Research Laboratory of Electrical Engineering and Automatic (LREA), Department of Electrical Engineering, University of \\ Medea, Algeria, 2600. \\ b. Department of Electrical Engineering, University of Djelfa, Algeria.
}

Received 10 November 2015; received in revised form 24 November 2016; accepted 6 March 2017

KEYWORDS
Asynchronous
machine;
Energy storage;
Wind turbine;
DTC-SVPWM;
Direct torque control;
Wind energy
conversion.

\section{Introduction}

Wind generators are generators whose primary energy source is wind. It is well known that the wind has very fluctuating and unpredictable characteristics. Even if there are statistical evaluations to predict the average values of the wind for a few days or the whole year, the wind speed changes very frequently and it is impossible to predict its value for the given time. As the mechanical power output from the wind turbine is very fluid, the electric power generated by the wind generator will also be very volatile [1-4] This poses many problems for administrators of the energy system for two reasons; first, it is necessary to ensure

*. Corresponding author. Tel.: +21 3792150261 E-mail address: amoualdia1@yahoo.fr (A. Moualdia)

doi: $10.24200 /$ sci.2017.4379 the balance between power generation and power consumption; thus, the wind generator should provide the energy that the consumer demands, not more or less. Second, the power consumption is very unpredictable and variable. Because of these restrictions, current wind generators cannot operate without SISES. The concept of storage is imperative associated with the generation of electricity. Whether it is an independent production (isolated site, embedded application, etc.) or production interconnected with the distribution network, the existence of buffers between production and consumption is essential. Electricity cannot be stored easily and requires transformation into another form of energy. The storage of electrical energy is a component of the future sustainable development. It often goes through an intermediate form (gravity, compression, chemical kinetics, mechanics, etc.) [5-8]. In this work, we will focus on storage modes that can be associated with a wind turbine. The purpose is 


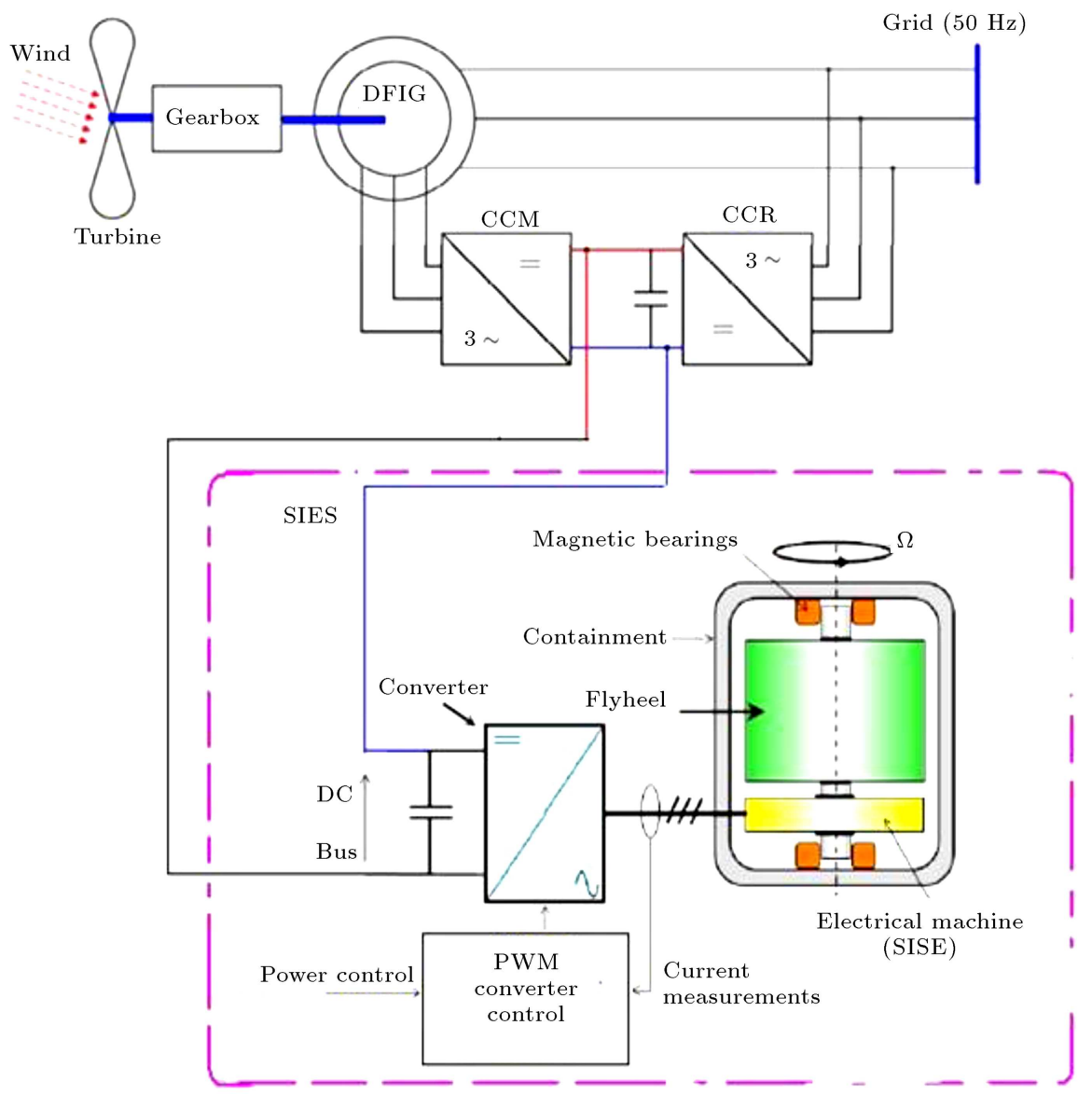

Figure 1. Inertial system for electrical energy storage.

twofold: to store electrical energy during periods of high wind in order to be able to return in periods of low wind, and to smooth maximum power generated by wind together with storing more energy. Storage is usually in a form other than electricity and, therefore, requires energy conversion. The overall performance of storage is very variable depending on the selected processes. There are two types of storage, one shortterm and the other long-term. In our case, we worked on short-term storage systems. They allow to quickly transfer high power over periods ranging from seconds to ten minutes. Inertial energy storage system (SISE) comprises a flywheel coupled with an electric machine operable in two modes: motor or generator. Inertial energy storage systems have time constants from few minutes up to several hours, depending on their design. The BIOS has found a specific application in improving the quality of electrical power. The frequency and voltage of the grid are imposed by regulators because of their strong momentum, good performance, and long lifetime. Inertial energy storage systems can be differentiated according to the speed range and the material from which the flywheel is manufactured. They are able to provide very high power and are limited only by the nominal power generators and power electronic converters. Currently, the most commonly used SISE is the asynchronous machine in SISES and notable achievements have already been reached for this type of machine. In 1996, an SISE with a 20 MW double-fed asynchronous machine and a flywheel of $74000 \mathrm{~kg}$ and $4 \mathrm{~m}$ in diameter was installed in Japan to regulate the frequency in a $132 \mathrm{kV}$ power line. The first applications of institutions within the wind fields considered the asynchronous machine cage and flying in slow inertia [7-10]. The majority of SISES with asynchronous machine are SISES with slow driving, but power electronic converters allow achieving the same quick-ruffle SISES with asynchronous machines. Furthermore, a very important advantage of asynchronous machines over other machines resides in the speed range at constant power. With appropriate dimensioning, this machine can attain a ratio of $X=5$. In this work, we will deal with the inertial energy storage system (called SISE). The storage system under study consists of inertial flywheel coupled with an induction motor and driven by a voltage inverter type power converter as presented in Figure 1. First, a model of SISE (flywheel + asynchronous machine) is presented and then, two control methods are proposed for the MAS, namely, Direct Torque Control (DTC) and DTC-SVPWM. The 
two control methods give similar performance, but the DTC-SVPWM requires less computation time. The two regulators and the proportional integrator SVPWM technique are used to determine the switching frequency. Using direct control with vector modulation strategy enables the SISE to achieve good continuation, even under rather severe operating conditions, and the torque ripples are significantly reduced compared to the case of conventional DTC. Simulation results of the two checks are provided.

\section{Mathematical modeling of the components of SISE}

Several types of electrical machines can be integrated into an SIES; the choice of the machine is made by taking into account some criteria, namely, the type of SIES (mobile or stationary), application (improving the quality of electrical power), the total cost of the system, the desired performance of the system, and the speed range of the system. Figure 2 shows torque and power of an electric machine. In this figure, there are two areas of operation for the machine $[10,11]$.

Operation is below the base speed in this area. Also, the nominal torque of the machine is available. However, the maximum power is variable, depending on the speed, and smaller than the nominal power. This area does not have much interest in the SIES. For operation above the base speed, the torque is reduced in order to limit the power of the machine to the rated value. It is the area of operation used in the SIES, where the rated power is available for any speed:

$$
X=\frac{\Omega_{\max }}{\Omega_{b}} .
$$

The report characterizes $X$ machine perspective constant power operation. A machine having $X=2$ allows operation at constant power between $50 \%$ and $100 \%$ of

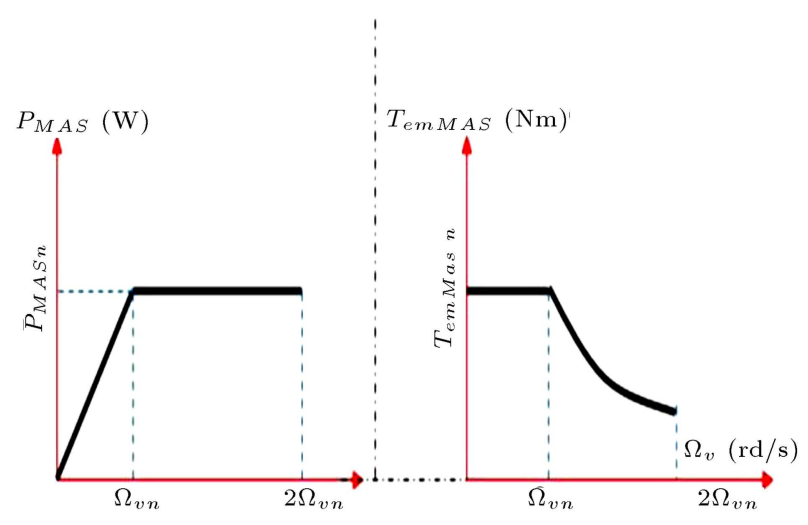

(a)

(b)

Figure 2. Envelopes of the power and electromagnetic torque of an electric machine. rated speed. This means you can enjoy $75 \%$ of the energy stored in the flywheel energy. Thus, the choice of the nominal electric machine power is made only on the basis of the nominal power of SIES [12].

\subsection{Modeling of the flywheel}

Expression of the energy stored in the flywheel is:

$$
\begin{aligned}
& E_{v}=\frac{1}{2} J_{v} \cdot \Omega_{v}^{2}, \\
& \varphi_{r n} \approx \frac{L_{r m a s} \cdot \varphi_{s n}}{M} \text { with } \varphi_{s n}=\frac{\sqrt{3} \cdot V_{s n}}{\omega_{s}} .
\end{aligned}
$$

We want to control the power of the flywheel coupled asynchronous machine by a reference power that should be stored or restored, represented by $P_{V r e f}$, and measure the speed of rotation of the flywheel by the following equation:

$$
\Omega_{v_{-r e f}}=\sqrt{\frac{2 \cdot E_{c v}}{J_{v}}} .
$$

\section{Direct torque control of asynchronous machine}

Direct Torque Control (DTC) is based on flow control and torque using hysteresis controllers [13,14]. The stator flux is estimated by the equation of stator voltage of asynchronous machine:

$$
\frac{d \overline{\varphi_{s}}}{d t}=\overline{V_{s}}-R_{s m a s} \cdot \overline{I_{s}}
$$

In $\alpha \beta$ repository, the components of the stator flux are determined as follows:

$$
\begin{aligned}
\varphi_{s \alpha} & =\int\left(-R_{s m a s} \cdot i_{s \alpha}+V_{s \alpha}\right) d t, \\
\varphi_{s \beta} & =\int\left(-R_{s m a s} \cdot i_{s \beta}+V_{s \beta}\right) d t .
\end{aligned}
$$

Currents and voltages in the $\alpha \beta$ system are determined from the three-phase variables using the transformation of Concordia. Being very difficult to be measured at the terminals of a three-phase inverter voltage supply, voltages are estimated based on the DC bus voltage and switching states of the inverter arm. Therefore, the phase voltages of the MAS are determined as follows $[14,15]$ :

$$
\begin{aligned}
& V_{a}=\frac{V_{d c}}{3}\left(2 . S_{a}-S_{b}-S_{c}\right), \\
& V_{b}=\frac{V_{d c}}{3}\left(2 . S_{b}-S_{a}-S_{c}\right), \\
& V_{c}=\frac{V_{d c}}{3}\left(2 . S_{c}-S_{b}-S_{a}\right) .
\end{aligned}
$$


A three-phase inverter can produce 8 different combinations as follows:

$$
\begin{gathered}
V_{0}(000), V_{1}(100), V_{2}(110), V_{3}(010), V_{4}(011), \\
V_{5}(001), V_{6}(101), V_{7}(111) .
\end{gathered}
$$

The 8 combinations generate 8 voltage vectors that can be applied across the asynchronous machine. The magnitude of the stator flux and the angle can be calculated from Eq. (5):

$$
\begin{aligned}
& \varphi_{s}=\sqrt{\varphi_{s \alpha}^{2}+\varphi_{s \beta}^{2}}, \\
& \theta_{s}=\operatorname{arctg}\left(\frac{\varphi_{s \beta}}{\varphi_{s \alpha}}\right) .
\end{aligned}
$$

In the $N_{i}$ sector, the stator flux vector is determined from the angle between the reference $(s)$ and flux vector. The electromagnetic torque of the Asynchronous machine is estimated by the following equation:

$$
\begin{aligned}
& T_{e m}=p \cdot\left(i_{s \beta \_m e s} \cdot \varphi_{s \alpha}-i_{s \alpha}{ }_{m} e s \cdot \varphi_{s \beta}\right) . \\
& \Delta \overline{\varphi_{s}}=\overline{V_{s}} \cdot T_{e} .
\end{aligned}
$$

Figure 3 gives information about the variation of the switching frequency of the inverter. It is seen that the commutations are denser when the position of the flux vector approaches the position of one of the voltage vectors. This is a very simple case assuming that the couple still has its reference value and only stream error generates switching voltage vectors. In reality, the flow path is much more complicated. Hysteresis regulators
Table 1. Sequence examples of voltage vectors and inner hysteresis band.

\begin{tabular}{cccccccc}
\hline $\boldsymbol{N}$ & $\mathbf{1}$ & $\mathbf{2}$ & $\mathbf{3}$ & $\mathbf{4}$ & $\mathbf{5}$ & $\mathbf{6}$ \\
\hline & $e_{c}=1$ & $V_{2}$ & $V_{3}$ & $V_{4}$ & $V_{5}$ & $V_{6}$ & $V_{1}$ \\
$e_{\varphi}=1$ & $e_{c}=0$ & $V_{7}$ & $V_{0}$ & $V_{7}$ & $V_{0}$ & $V_{7}$ & $V_{0}$ \\
& $e_{c}=-1$ & $V_{6}$ & $V_{1}$ & $V_{2}$ & $V_{3}$ & $V_{4}$ & $V_{5}$ \\
& & & & & & & \\
$e_{\varphi}=0$ & $e_{c}=1$ & $V_{3}$ & $V_{4}$ & $V_{5}$ & $V_{6}$ & $V_{1}$ & $V_{2}$ \\
& $e_{c}=0$ & $V_{0}$ & $V_{7}$ & $V_{0}$ & $V_{7}$ & $V_{0}$ & $V_{7}$ \\
& $e_{c}=-1$ & $V_{5}$ & $V_{6}$ & $V_{1}$ & $V_{2}$ & $V_{3}$ & $V_{4}$ \\
\hline
\end{tabular}

receive torque error and flow as the input and provide discrete output signals.

Based on the outputs of the regulators and the hysteresis area $(N)$, where the stator flux is located, the voltage vectors are selected to maintain the flux and torque of the internal hysteresis bands. Table 1 gives the possible selections.

\section{Direct torque control-space vector modulation}

The proposed method preserves the basic idea of the classical DTC method. For this, technical orientation of the stator flux is used. The control voltages can be generated by PI controllers and imposed by SVPWM technique. This control structure has the advantages of
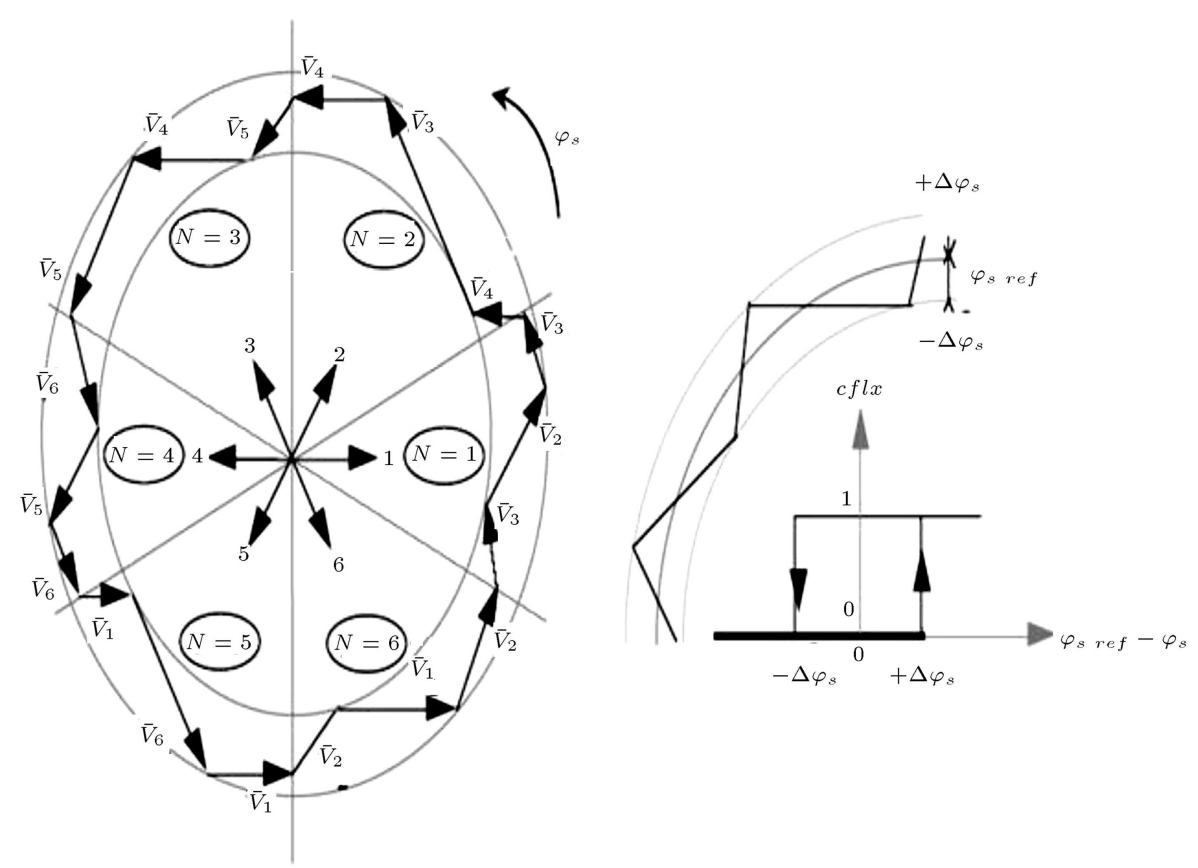

Figure 3. Sequence examples of voltage vectors and inner hysteresis band. 


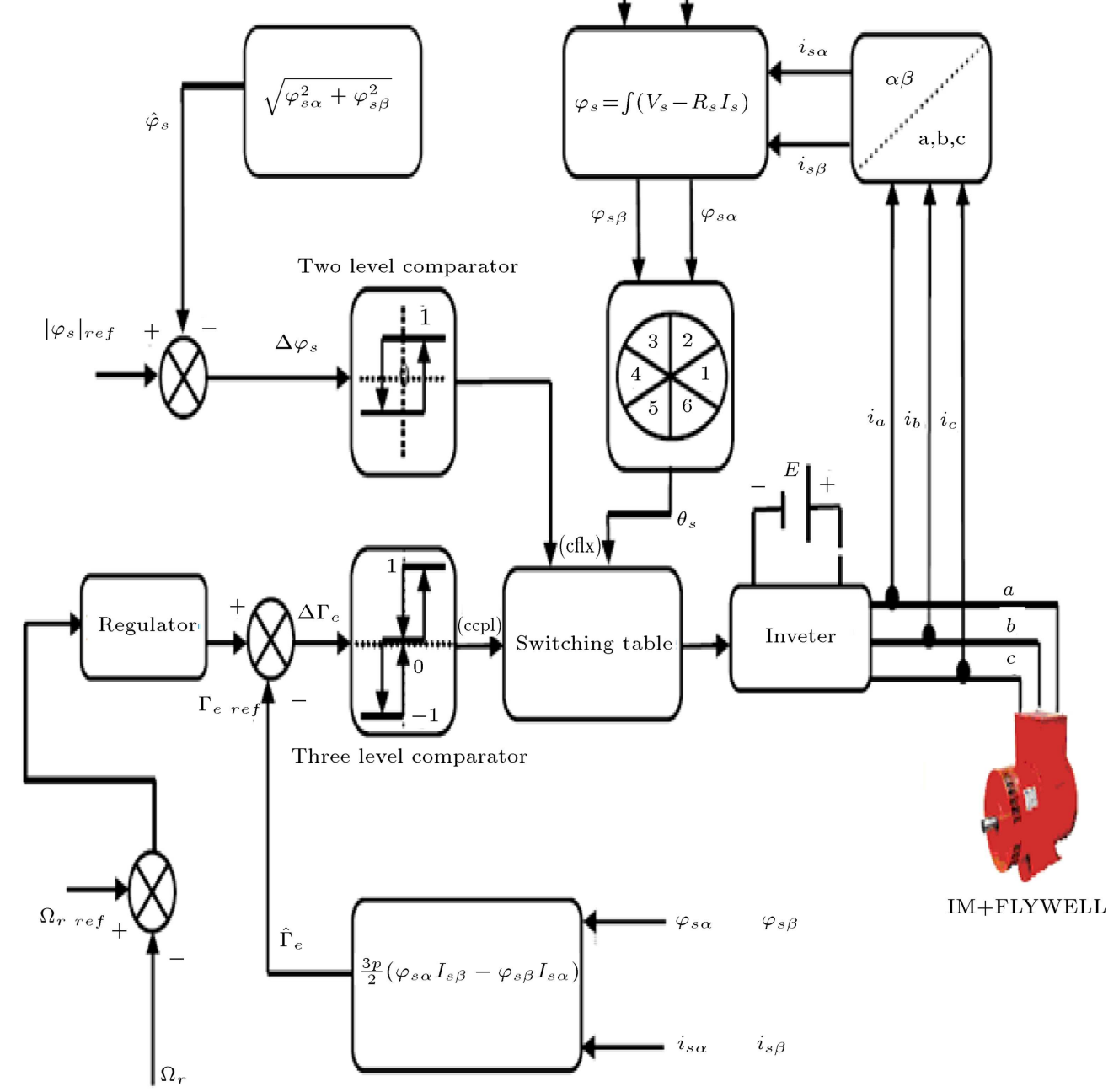

Figure 4. The block diagram of the DTC SIES.

vector control and direct torque control and allows for surpassing the problems of the classical DTC $[16,17]$. The PI regulator and vector modulation technique is used to obtain a fixed switching frequency and less torque pulsations and flow. The block diagram of the structure is illustrated in Figure 4.

Two PI controllers are used for controlling the flux and torque. Stages of the implementation of a Vector PWM Modulation (SVPWM) are illustrated by the block diagram of Matlab/Simulink in Figure 5. In addition, the results are presented in Figure 6.

\section{Simulation results}

The block diagrams of the two methods (conventional DTC and DTC-SVPWM), illustrated in Figure 7, were implanted in MATLAB/Simulink software to simulate the inertial storage system (SIES). Initially, the machine was not run and only the flux was maintained at nominal value; then, it started with the speed of $314 \mathrm{rd} / \mathrm{s}$.

It was assumed that the machine had an initial energy of $E_{c 0}=1 \mathrm{~kJ}$. Control power and the electrical power storage system are shown in Figure 8 . It shows the simulation results for the case where the network requires a variable-power SIES. Asynchronous machine with bipolar pairs (4 Kw at $1500 \mathrm{rpm}$ ) and a flywheel having $J=0.2 \mathrm{~kg} \cdot \mathrm{m}^{2}$ was considered in the simulations.

According to Figure 9, the measured velocity is well below the imposed reference. Figure $9(\mathrm{~b})$ shows how the block has been weakened by the estimated rotor flux and flux reference. This implies that the speed controller is properly sized.

Figure 10 illustrates the evolution of the energy stored in the flywheel. The electromagnetic torque is shown in Figure 11; it varies in a way to keep the power constant and flywheel below its reference 


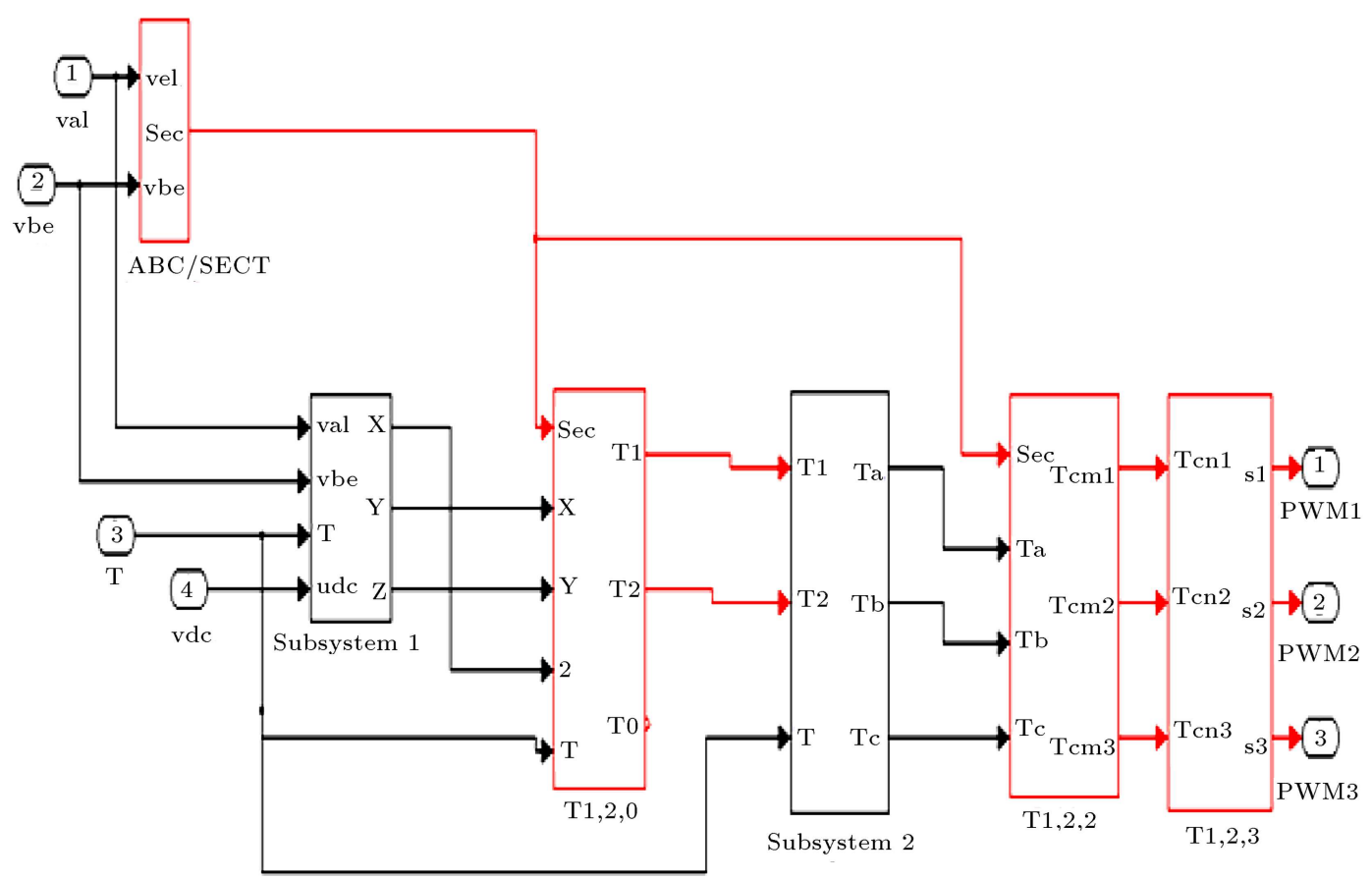

Figure 5. Simulink subsystems of SVPWM.
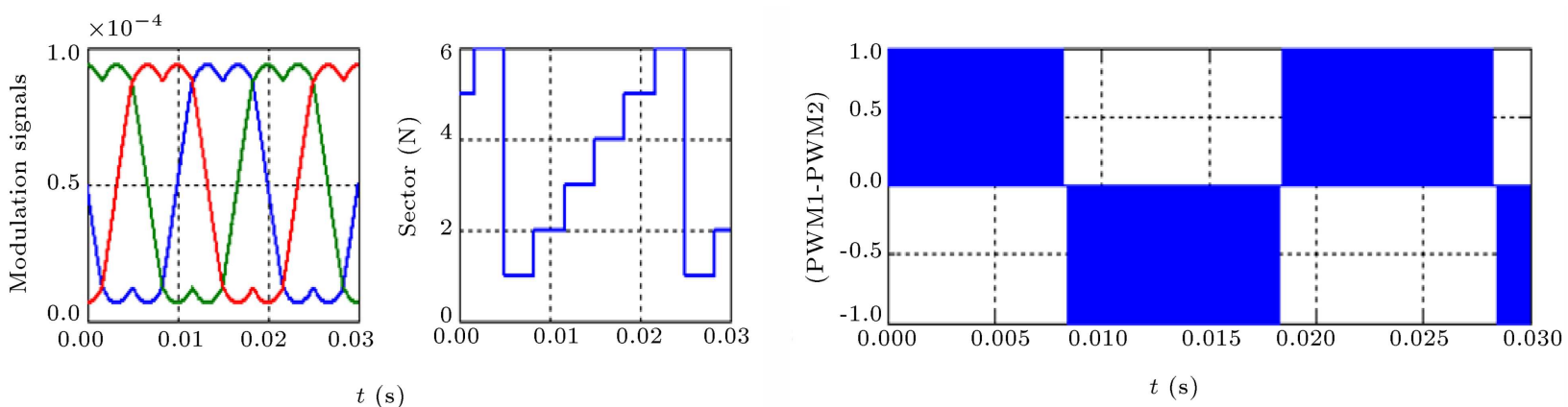

$t(\mathrm{~s})$

Figure 6. Modulation signal, the sector, and PWM signal.

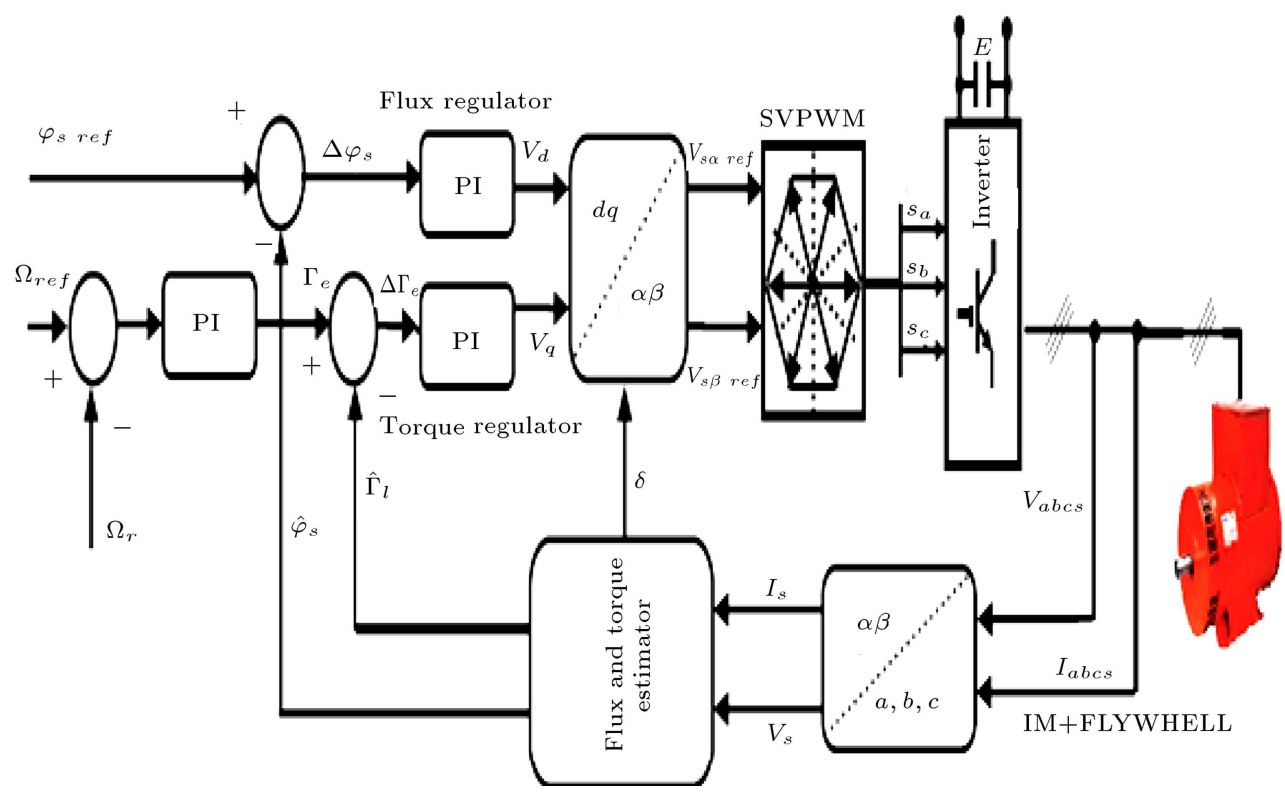

Figure 7. Simulation results of the SVPWM algorithm. 


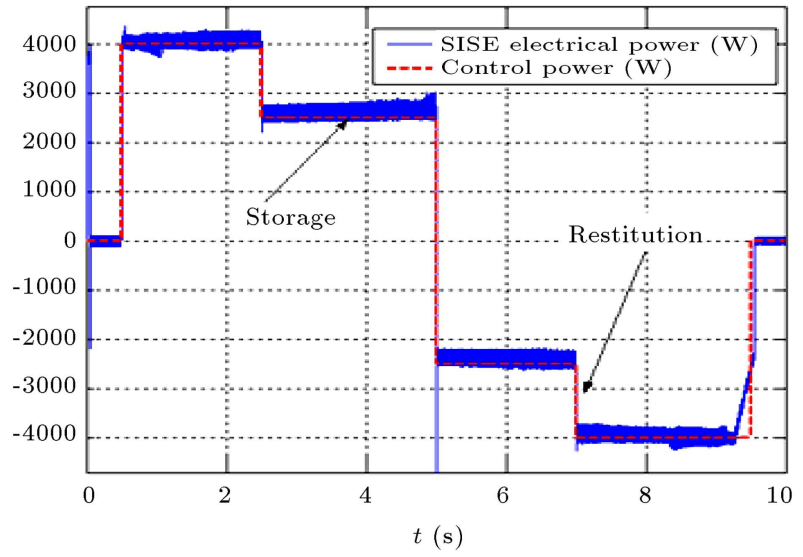

Figure 8. Electrical power of SIES and control power.

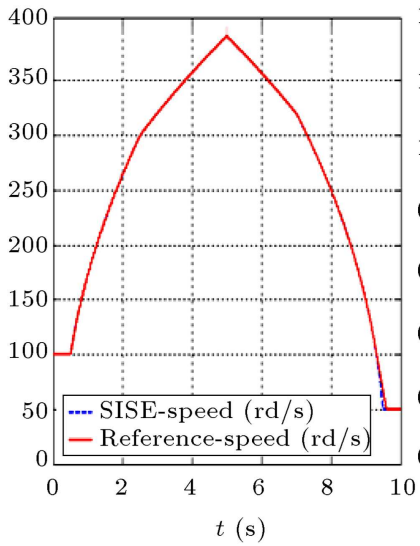

(a)

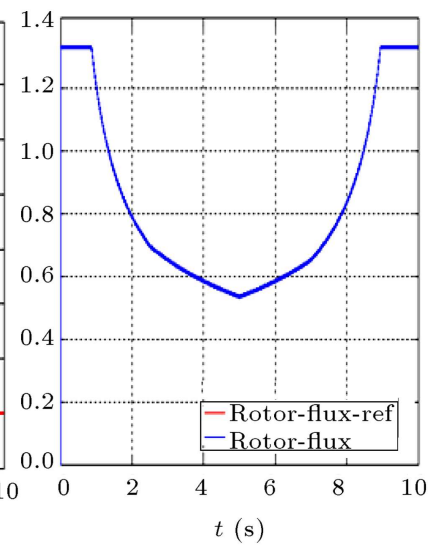

(b)
Figure 9. (a) Flywheel speed and reference. (b) Rotor flux.

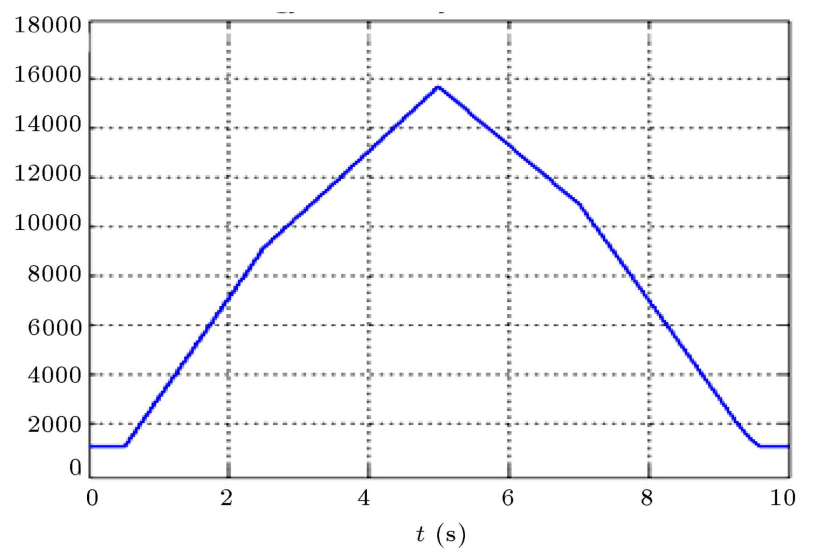

Figure 10. Energy stored in flywheel.

from the speed regulator. The variation of the flux in the reference trajectory $(\alpha \beta)$ is presented in Figure 12 .

The phase currents of the SIES are shown in Figure 13. Moreover, the operating modes are illustrated in Figure 14(a) for the cases of storage; there is an increase in the speed of the flywheel. Figure 14(b)

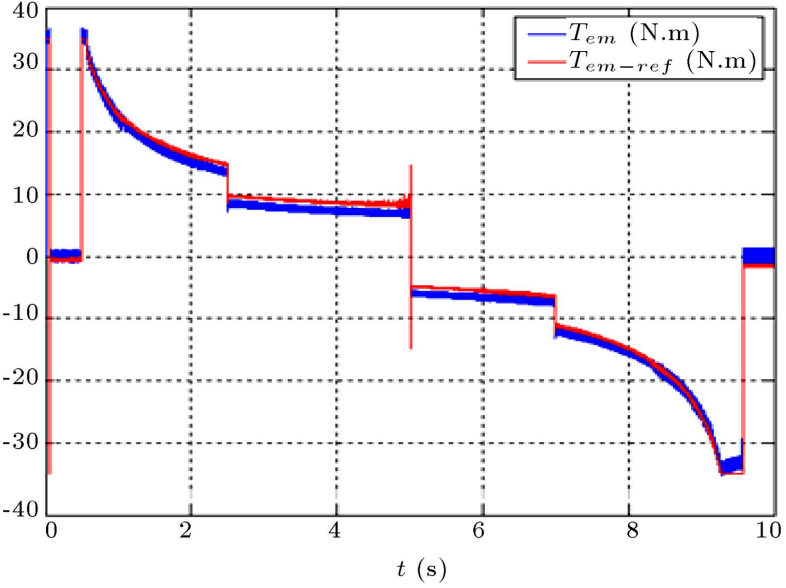

Figure 11. Electromagnetic torque and reference torque.

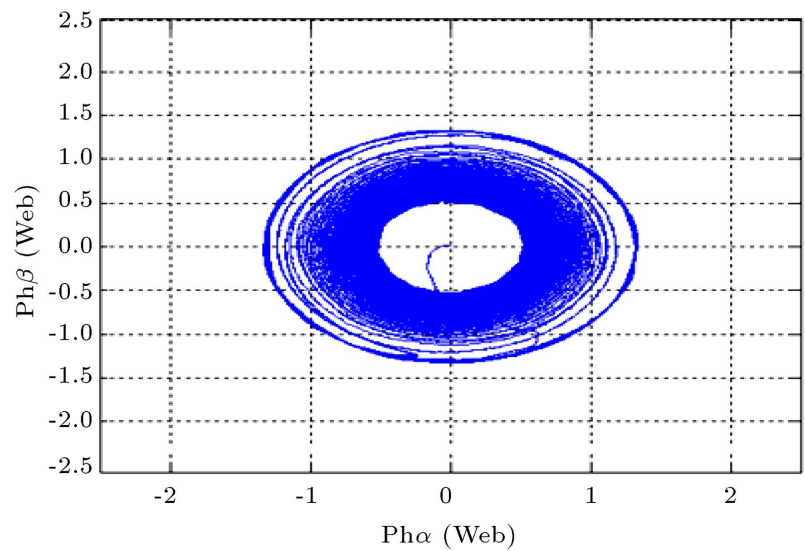

Figure 12. Stator flux in reference $(\alpha \beta)$ trajectory.

shows the cases of restitution and the results show a decrease in speed. Simulation results show that direct torque control with PWM Vector DTC-SVPWM for SIES gives good outcomes in comparison with the conventional DTC control. It is important to note that under the proposed DTC-SVPWM control, SIES shows good pursuit, even under operating conditions that are severe enough, and the torque ripples are significantly reduced compared with the case of conventional DTC.

\section{Conclusion}

The model met the objectives. The simulation results clearly showed the storage and retrieval of energy. The mathematical model of inertial energy storage system was presented and the methods of control (conventional DTC and DTC-SVPWM) for asynchronous machine cage were used. Both control methods gave similar performance, but the DTC-SVPWM required less computation time. The two controllers and the proportional integrator SVPWM technique were used to set the switching frequency. The use of direct control with vector modulation strategy enabled the 


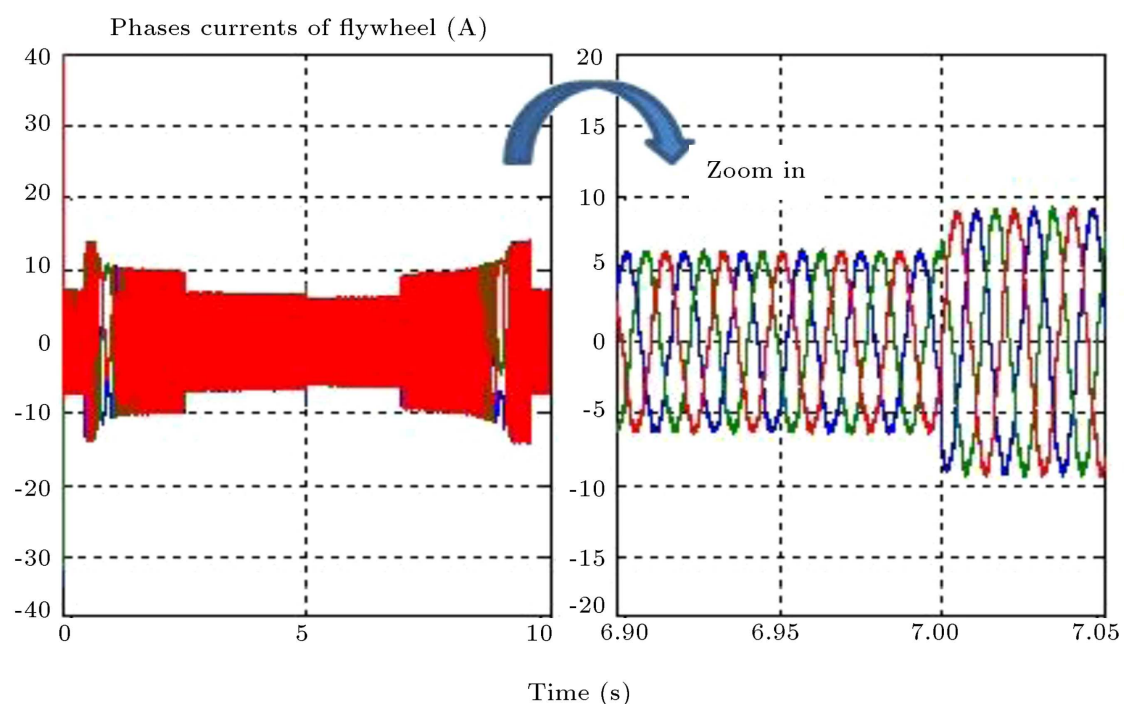

Figure 13. Phases current of flywheel SIES.

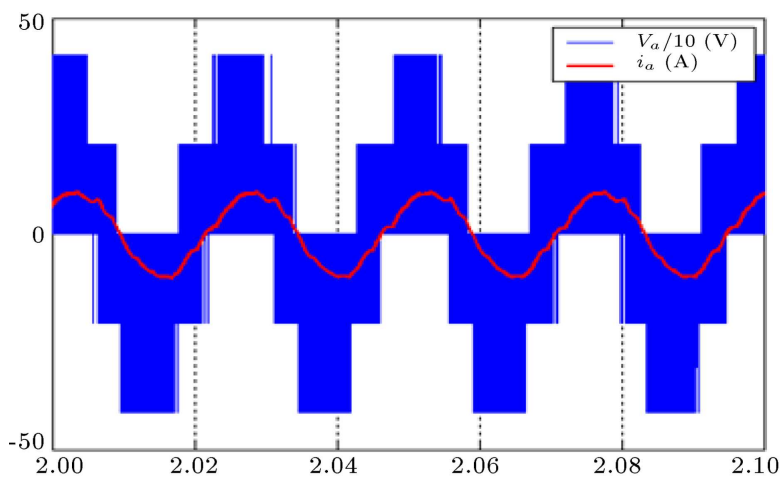

(a)

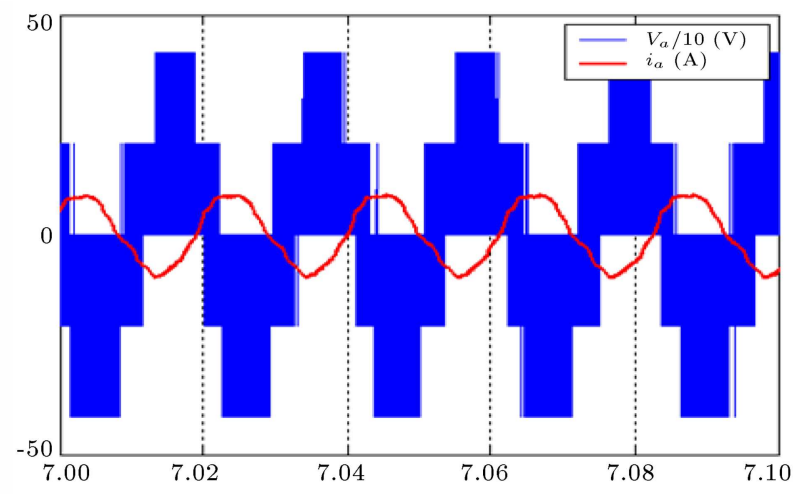

(b)

Figure 14. (a) Energy storage period. (b) Energy restitution period.

SIES to show good tracking, even under operating conditions that were severe enough, and the torque ripples were significantly reduced compared with the case of conventional DTC.

\section{Acknowledgements}

The work presented in this publication was carried out in LREA Laboratory of Research in Electrical and Automatic, University of Medea, under the scientific direction of Mr. M. Mahmoudi, Professor, in the National Polytechnic School of Algeria, and Mr. L. Nezli, conference teacher in the National Polytechnic School of Algeria, to whom the authors express their deep gratitude for all the advice and encouragement they provided during the entire stages of the work, despite being busy.

\section{Nomenclature}

$E_{v} \quad$ Energy stored in the flywheel
$P_{v} \quad$ Power of the flywheel

$J_{v} \quad$ Coefficient of inertia

$\Omega_{v} \quad$ Flywheel speed

$\varphi \quad$ Flux (Wb)

$T_{e m} \quad$ Electromagnetic torque $(\mathrm{Nm})$

$L_{s}\left(L_{r}\right) \quad$ Stator inductance (rotor) $(\mathrm{H})$

$M \quad$ Mutual inductance $(\mathrm{H})$

$\sum$ Leakage coefficient $\sigma=1-M_{2} / L_{s} L_{r}$

$R_{s}\left(R_{r}\right) \quad$ Stator resistance (rotor) $(\Omega)$

$\theta r \quad$ Rotor position

$\omega_{r}\left(\omega_{s}\right) \quad$ Rotor and stator pulsation $(\mathrm{rd} / \mathrm{s})$

$G \quad$ Slip

$P \quad$ Number of pole

$P_{\text {mas }} N \quad$ Rated Power of asynchronous machine

DTC Direct Torque Control

SVPWM Space vector modulation

IESS Inertial Energy Storage System 


\section{References}

1. Hu, J. and He, Y. "DFIG wind generation systems operating with limited converter rating considered under unbalanced network conditions analysis and control design", Renew Energy, 36(2), pp. 829-847 (2011).

2. Susperregu, A., Tapia, G., Zubia, I., and Ostolaza, J.X. "Sliding-mode control of doubly-fed generator for optimum power curve tracking", Int. J. of Electron Lett., 46(2), pp. 126-127 (2010).

3. Hu, J., Nian, H., Xu, H., and He, Y. "Dynamic modeling and improved control of DFIG under distorted grid voltage conditions", IEEE Trans. Energy Convers, 26(1), pp. 163-175 (2011).

4. Kairous, D., Wamkeue, R., and Belmadani, B. "Sliding mode control of DFIG based variable speed WECS with flywheel energy storage", Int. Conf. on Electrical Machines - IEEE, Rome (2010).

5. Pena, R., Cardenas, J., Proboste, G., and Clare, J. "Sensorless control of doubly-fed induction generators using a rotor-current-based MRAS observer", IEEE Trans. Ind. Electron., 55(1), pp. 330-339 (2008).

6. Martinez, M.I.G., Tapia, Susperregui, A., and Camblong, H. "DFIG power generation capability and feasibility regions under unbalanced grid voltage conditions", IEEE Trans. Energy Convers., 26(4), pp. 10511062 (2011).

7. Poitiers, F., Bouaouiche, T., and Machmoum, M. "Advanced control of a doubly-fed induction generator for wind energy conversion", Int. J. of Electric Power Systems Research, 79(7), pp. 1085-1096 (2009).

8. Lin, H., Yan, W., Wang, J., Yao, Y., and Gao, B. "Robust nonlinear speed control for a brushless DC motor using model reference adaptive backstepping approach", Int Conf on Mech. and Automation, Changchun, China, pp. 335-340 (2009).

9. Kiani, M. and Lee, W.J. "Effects of voltage unbalance and system harmonics on the performance of doublyfed induction wind generators", IEEE Trans. Ind. Appl., 46(2), pp. 562-568 (2010).

10. Khaterchi, M., Belhadj, J., and Elleuch, M. "Participation of direct drive wind turbine to the grid ancillary services using a flywheel energy Storage system", 7th Int Multi-Conf on Sys., Signals. and Devices, IEEE (2010).

11. Zhou, P., He, J., and Sun, D. "Improved direct power control of a DFIG based wind turbine during network unbalance", IEEE Trans. Power Electron, 24(11), pp. 2465-2474 (2009).

12. Belfedhal, S. and Berkouk, M. "Modeling and control of wind power conversion system with a flywheel energy storage system", Int. J. of Renewable Energy Research, 1(3), pp. 43-52 (2011).
13. Chau, K.T. and Chen, J.H. "Modeling, analysis, and experimentation of chaos in a switched reluctance drive system", IEEE Trans. on Circuit. and Systems-I: Fund Theory. and Appl, 50(5), pp. 712-716 (2003).

14. Wang, Z. and Chau, K.T. "Anti-control of chaos of a permanent magnet DC motor system for vibratory compactors", Int. J. of Chaos, Soli. and Fractals, 36(3), pp. 694-708 (2008).

15. Devon, M., Richard, P., and Nicholus, M. "The role of energy storage in the grid", IEEE Power and Energy Magazine, 18 June (2012).

16. Liserre, M., Cárdenas, R., Molinas, M., and Rodríguez, J. "Overview of multi-MW wind turbines and wind parks", IEEE Trans on Industrial Electronics, 58(4), pp. 1081-1095 (2011).

17. Torben, K., Thomas, B., and Mohsen, S. "Prediction models for wind speed at turbine locations in a wind farm", Int. J. of Wind Energ., 14(7), pp. 877-894 (2011).

\section{Appendix}

Asynchronous machine parameters are as follows:

$\begin{array}{ll}\text { Power } & 4 \mathrm{~kW} \\ \text { Rated speed } & 1440 \mathrm{rpm} \\ \text { Rated torque } & 27 \mathrm{Nm} \\ \text { Rotor resistance } & 1.8 \Omega \\ \text { Stator resistance } & 1.2 \Omega \\ \text { Rotor inductance } & 0.15687 \mathrm{H} \\ \text { Stator inductance } & 0.1554 \mathrm{H} \\ \text { Moment of inertia } & 0.2 \mathrm{~kg} \cdot \mathrm{m}^{2} \\ \text { Coefficient of viscous friction } & 0.001 \mathrm{k} \cdot \mathrm{m}^{2} / \mathrm{s} \\ \text { Number of poles } 2 & \end{array}$

\section{Biographies}

Abdelhafidh Moualdia was born in February, 1970, in Algeria. He received the BEng degree in Electrical Machines in 1995 and the MEng degree in Electrical Engineering in 2004 from University of Medea, and the PhD degree in Automatic in 2014 from National Polytechnic School. He is currently an Associate Professor in Electrical Engineering Department at the University of Medea. His research interests are power electronics, electric machines, and wind energy conversion.

Ahmed Medjber was born on February 2, 1973, in Medea, Algeria. He received the Diploma of Engineering in Electronics Option Control from the University of Blida in 2000 and the MEng degree in Electronics Option Signal and System from University of Blida, Algeria, in 2008.

Abdellah Kouzou is currently with the Applied Automation and Industrial Diagnostic Laboratory at 
University of Djelfa 17000 DZ, Algeria. He is Editorin-Chief of IJAEE Journal, Editor-in-Chief of IJRESS International Journal of Renewable Energy Sources and Systems, IEEE Senior Member, and Collaborating Researcher with Texas A\&M University.

Ouahid Bouchhida received the BEng degree in Electrical Machines in 1995 and the MEng degree in Electrical Engineering in 1998 from University of Sciences and Technology of Algiers USTHB, and the PhD degree in Automatic in 2008 from National Polytechnic School. He is currently an Associate Professor in Electrical Engineering Department at the University of Medea. His research interests are power electronics, electric machines, and variable speed drive. 